\title{
What Are These Dark Brown Patches on the Sole of a Boy's Foot?
}

Erika C. Malana, $\mathrm{BMSc}^{1}$ - Michelle L. Gallagher, $\mathrm{DO}^{2}$

A 9-year-old boy presented to our clinic with skin discoloration on the sole of his right foot that appeared abruptly 3 weeks prior to presentation. His mother said that the discoloration may have slightly faded since the initial presentation.

A skin examination revealed asymmetric, irregular, poorly demarcated brown patches that were darker than the surrounding skin on the patient's right plantar surface and plantar surface of his right first toe (Figure 1). The numerous patches ranged in size from $1.5 \mathrm{~cm}$ in diameter to $3 \times 7 \mathrm{~cm}$. A congenital nevus was also present on the right knee, which was stable from the last examination. The rest of the integumentary examination of the head, face, hands, and left foot were unremarkable.

There were no associated or preceding rashes, pain, pruritis, erythema, or constitutional symptoms. Family history of similar discoloration was negative. At presentation, the patient appeared pleasant, well-developed, well-nourished, alert, and oriented.

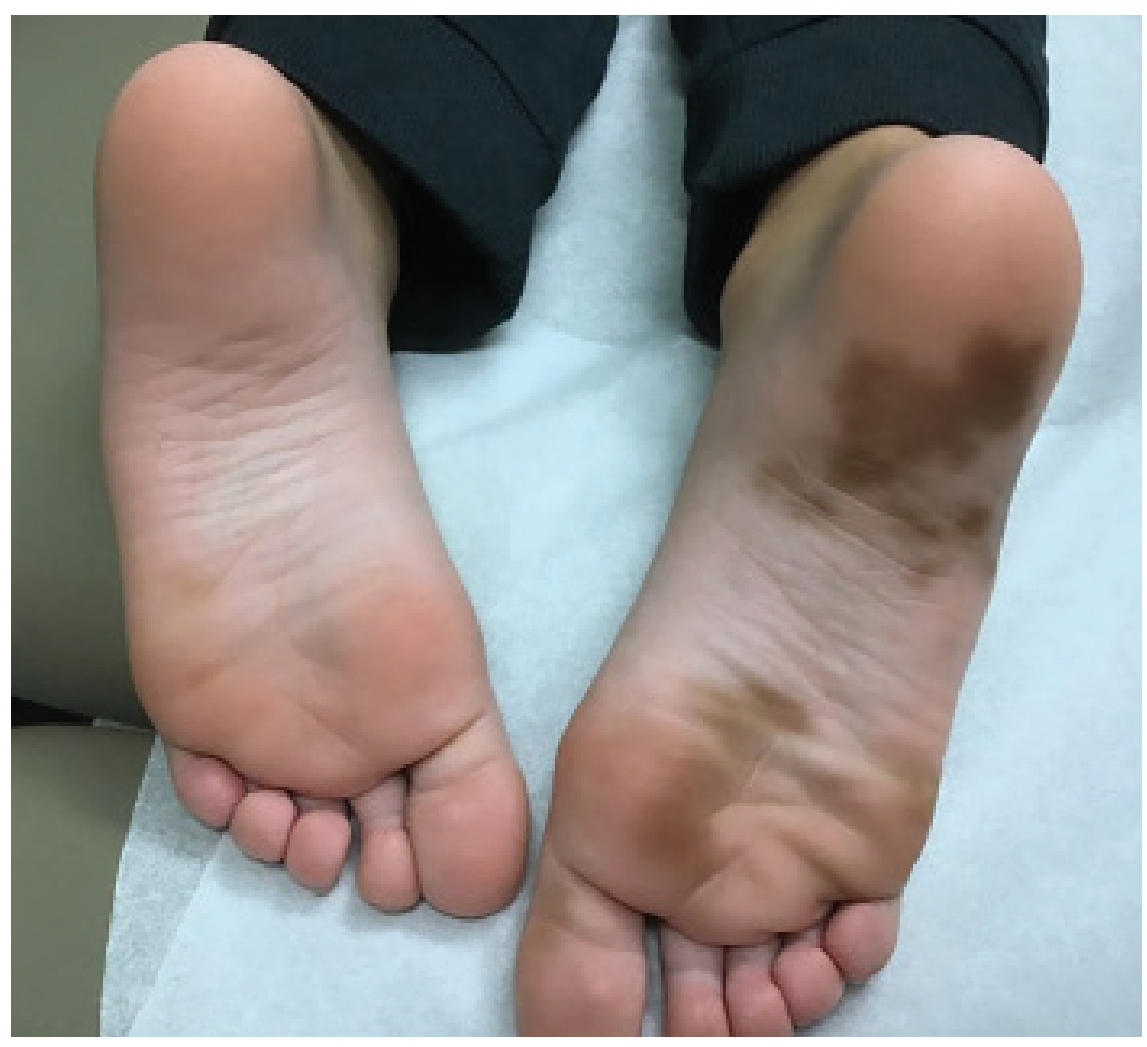

Figure 1. Brown patches were noted on the patient's right plantar surface and plantar surface of his right first toe.

\section{AFFILIATIONS:}

${ }^{1}$ Medical Student, Michigan State University College of Osteopathic Medicine, East Lansing, Michigan

${ }^{2}$ Assistant Professor, Department of Pediatrics, Michigan State University College of Osteopathic Medicine, East Lansing, Michigan

\section{CITATION:}

Malana EC, Gallagher ML. What are these dark brown patches on the sole of a boy's foot? Consultant. Published online May 24, 2021. doi:10.25270/con.2021.05.00010

Received January 14, 2021. Accepted January 29, 2021.

\section{DISCLOSURES:}

The authors report no relevant financial relationships.

\section{CORRESPONDENCE:}

Erika C. Malana, BMSc, Michigan State University College of Osteopathic Medicine, 965 Wilson Road, East Lansing, MI 48824 (malanaer@msu.edu)
What was the cause of the discoloration?
A. Black walnut staining
B. Dermal melanocytosis
C. Hypocortisolism
D. Melanoma

\section{Answer: A. Black walnut staining}

Given the patient's unremarkable history and the mother's denial of any known exposure to black walnuts, a diagnosis of exclusion was made for post-inflammatory hyperpigmentation 


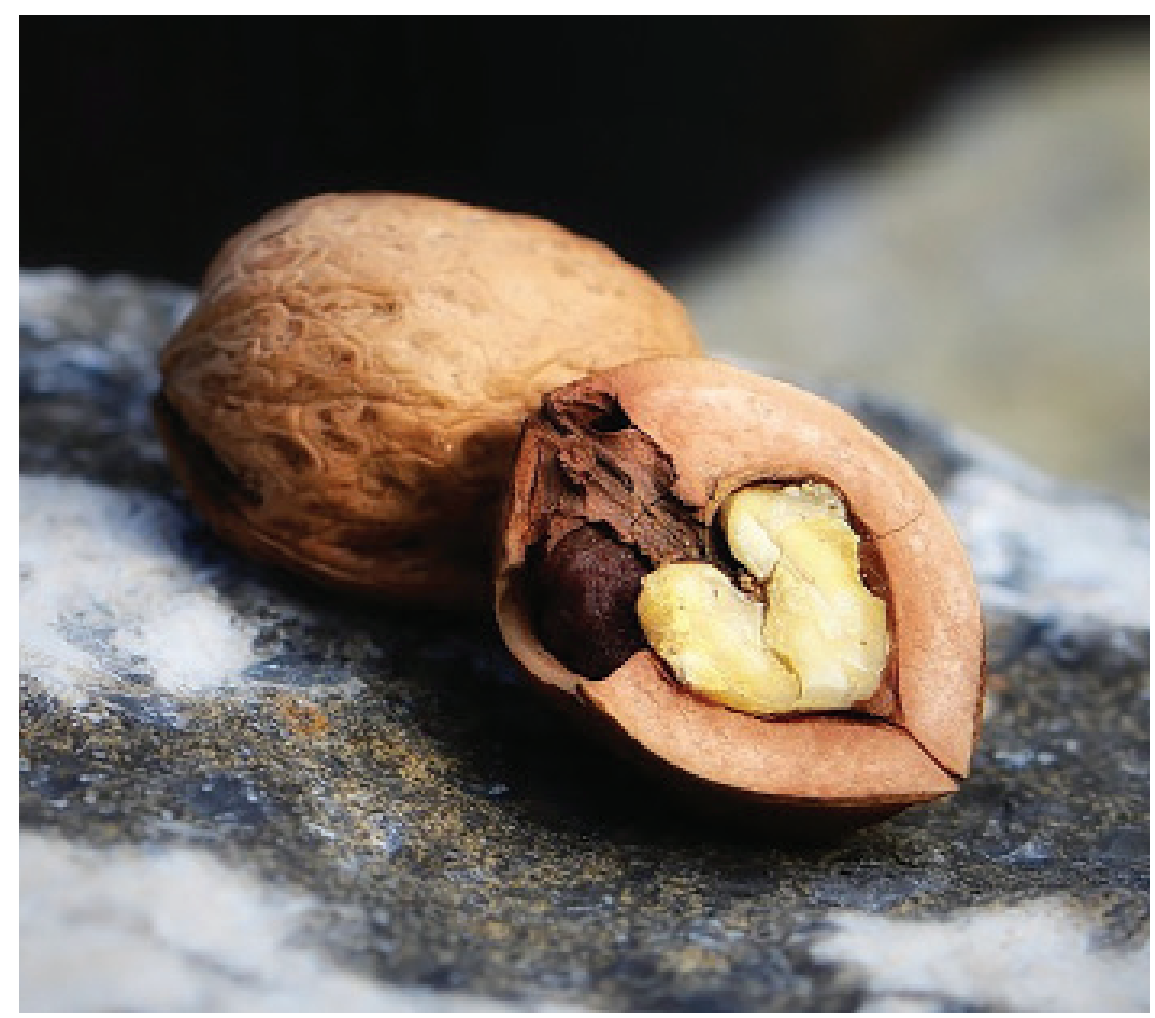

Figure 2. Black walnuts are common in central and eastern parts of the United States and southern Ontario, Canada.

(PIH). The mother was counseled that $\mathrm{PIH}$ describes darker discoloration of the skin resulting from prior skin trauma or rashes and that areas tend to normalize on their own over time, taking up to months or even years. However, with a high degree of clinical suspicion for black walnut staining, the attending physician emailed the mother later that day with a picture of black walnuts, once again asking her whether there might have been prior exposure. The mother recognized the ubiquitous walnut in her yard, which prompted the change of diagnosis from $\mathrm{PIH}$ to exogenous pigmentation from tannins found in black walnuts. The attending physician counselled the mother that the discoloration should resolve on its own faster than $\mathrm{PIH}$ would and, that given the asymptomatic nature of the lesions, no additional treatments were indicated. The mother reported via a telephone follow-up that the pigment had completely faded by 2 weeks after the initial office visit.

\section{Discussion}

Black walnuts (Juglans nigra) are native to central and eastern parts of the United States as well as to southern Ontario, Canada (Figure 2). They are a valuable source of dark-stained wood furniture, and they are edible in baked goods and ice cream.

Patel and Castelo-Soccio reported similar findings to ours in their patient who had also been playing in a yard with fallen black walnuts. ${ }^{2}$ Similarly, Bishnoi and colleagues described how the act of hulling or husking, a process involving procuring the black walnut from its green husk, can lead to staining of the hands in the absence of dermatitis. ${ }^{3}$ However, cases of irritant contact dermatitis with black walnuts have been described and attributed to julandic acid in the walnut hull ${ }^{4}$ and juglone, ${ }^{5}$ a yellow pigment found in the plant's hull, leaves, roots, and bark. ${ }^{6}$

Dermal melanocytosis is characterized by blue-grey areas of discoloration caused by the presence of melanocytes in the dermis. Congenital dermal melanocytosis presents following birth and rarely persists past age 6 years. ${ }^{12}$ In normal development, melanocytes in the dermis either migrate to the epidermis or are cleared by macrophages, such that rarely do any remain in the dermis by week $20 .^{13}$ The etiology of acquired dermal melanocytosis is currently unknown, but cases report a gradual progression of the pigmented lesion.14-17 Our patient's lesion was neither present in infancy nor progressed gradually. Furthermore, its pigment can be described as a darker brown rather than blue-grey.

In the pediatric population, hypocortisolism caused by primary adrenal insufficiency is often the result of an underlying genetic component. ${ }^{7-9}$ The damaged adrenal glands release less cortisol, therefore exerting less negative feedback on the hypothalamus. As a result, the hypothalamus and pituitary gland release higher levels of various hormones, one of which is melanocyte-stimulating hormone $(\mathrm{MSH}) .^{10}$ The increase in melanin production caused by high $\mathrm{MSH}$ levels in epidermal melanocytes contributes to generalized and diffuse hyperpigmentation." As such, hypocorticolism is unlikely to present with acute, localized hyperpigmentation, as was the case with our patient. Furthermore, primary adrenal insufficiency classically presents with fatigue, decreased appetite, and weight loss, ${ }^{7}$ all of which were absent in our patient.

Melanoma arises from melanocytes and is the most serious form of skin cancer. The abrupt onset of hyperpigmentation in the presenting large area, as well as the patient's young age, prompted an early diagnostic exclusion of melanoma. The complete resolution within weeks is further evidence against a diagnosis of melanoma. Stashak and colleagues described a patient whose pigmented lesion 
mimicked acral lentiginous melanoma, a differential diagnosis that was ruled out following histopathologic examination. ${ }^{18}$ The final diagnosis was made when the patient later reported exposure to black walnuts, leaving readers with a final reminder from the authors to consider exogenous tissue dyeing in the differential diagnosis of acral pigmented lesions. ${ }^{18}$

\section{Conclusion}

Our case further demonstrates the importance of taking a thorough history and highlights the necessity of maintaining ongoing communication with patients to ensure that they understand what is being asked of them. In our patient's case, this included confirming exposure to a certain substance by emailing the family a picture of black walnuts.

\section{References}

1. Williams RD. Juglans nigra $L$., black walnut. In: Burns RM, Honkala BH, eds. Silvics of North America. Vol 2, Hardwoods. United States Department of Agriculture; 1990:391399. https://www.srs.fs.usda.gov/pubs/ misc/ag_654_vol2.pdf

2. Patel DP, Castelo-Soccio L. Image gallery: black walnut staining: an unusual presentation of exogenous pigmentation. Br J Dermatol, 2017;177(3):e76. https://doi. org/10.1111/bjd.15795

3. Bishnoi A, Vinay K, Kumaran SM. An elderly male with asymptomatic black staining of hands. Indian Dermatol Online J. 2020;11(1):103-104. https://doi.org/10.4103/
idoj.IDOJ_4_19

4. Siegel JM. Dermatitis due to black walnut juice. AMA Arch Derm Syphilol. 1954;70(4):511-513. https://doi.org/10.1001/ archderm.1954.01540220113015

5. Olvera-Cortés V, Pulido-Díaz N, Orellana-Arauco ÁR. Discoloration and bullous lesions on the hands. Cutis. 2019;104(4):E6E8. https://cdn.mdedge.com/files/ s3fs-public/CT104004006_e.PDF

6. Cosmulescu S, Trandafir I, Achim G, Baciu A. Juglone content in leaf and green husk of five walnut (Juglans regia L.) cultivars. Not Bot Hort Agrobot Cluj. 2011;39(1):237-240. http://dx.doi.org/10.15835/nbha3915728

7. Guran T, Buonocore F, Saka N, et al. Rare causes of primary adrenal insufficiency: genetic and clinical characterization of a large nationwide cohort. J Clin Endocrinol Metab. 2016;101(1):284-292. https://doi.org/10.1210/ jc.2015-3250

8. Roucher-Boulez F, Mallet-Motak D, Samara-Boustani $D$, et al. NNT mutations: a cause of primary adrenal insufficiency, oxidative stress and extra-adrenal defects. Eur J Endocrinol, 2016;175(1):73-84. https:// doi.org/10.1530/EJE-16-0056

9. Flück CE. Update on pathogenesis of primary adrenal insufficiency: beyond steroid enzyme deficiency and autoimmune adrenal destruction. Eur J Endocrinol. 2017;177(3):99-111. https://doi.org/10.1530/ EJE-17-0128

10. Erickson QL, Faleski EJ, Koops MK, et al. Addison's disease: the potentially life-threatening tan. Cutis. 2000;66(1):72-74. https://cdn.mdedge.com/files/s3fs-public/
Document/September-2017/066010072.pdf

11. Lause M, Kamboj A, Faith EF. Dermatologic manifestations of endocrine disorders. Transl Pediatr. 2017;6(4):300-312. https:// doi.org/10.21037/tp.2017.09.08

12. Gupta D, Thappa DM. Mongolian spots-a prospective study. Pediatr Dermatol. 2013;30(6):683-688. https://doi.org/10.1111/ pde.12191

13. Gupta D, Thappa DM. Mongolian spots. Indian I Dermatol Venereol Leprol. 2013;79(4):469-478. https://doi. org/10.4103/0378-6323.113074

14. Zhang $\mathrm{W}, \mathrm{Xu} X$, Sun J. Acquired dermal melanocytosis restricted to the hand. Eur J Dermatol, 2016;26(2):199-200. https://doi. org/10.1684/ejd.2015.2717

15. Kosumi H, Miyauchi T, Nomura T, et al. Diagnostic features of acquired dermal melanocytosis of the face and extremities. Clin Exp Dermatol. 2018;43(7):806-809. https:// doi.org/10.1111/ced.13546

16. Marín-Hernández E, Marín-González EJ, Siordia-Reyes G. Acquired dermal melanocytosis on the hand of a pediatric patient. Bol Med Hosp Infant Mex. 2019;76(6):294-297. https://doi.org/10.24875/BMHIM.19000135

17. Jun JY, Byun HJ, Oh SJ, Oh SH, Park JH, Lee $\mathrm{JH}$. Acquired dermal melanocytosis confined to the hand. Ann Dermatol. 2018;30(3):380-381. https://doi.org/10.5021/ ad.2018.30.3.380

18. Stashak AB, Laarman R, Fraga GR, et al. Exogenous pigmentation mimicking acral melanoma: a case of Talon d'Oyer. JAMA Dermatol. 2014;150(10):1117-1118. https://doi. org/10.1001/jamadermatol.2014.567 